\author{
Island Africa \\ Jonathan Kingdon \\ Collins, London, 1990, 287 \\ pp., HB $£ 25.00$
}

This is Jonathan Kingdon's first major book since his seven-volume series on East African mammals (1971-1982) and it deals with the several centres of endemism of plants and animals in the Afrotropical Region and surrounding islands in the Atlantic and Indian oceans. The introductory chapter considers endemism in relation to geology, climate change, vegetation change and other general aspects. The author points out that, while the speciation of plants tends to be on a considerably longer time scale than that of animals, endemism of both seems to have arisen at the same localities. Using the very localized balsams or jewelweeds, Impatiens spp., as an example, he also notes that, contrary to what is often assumed, most scarce endemics are rare and localized due to factors other than human activity. The essential dryness of much of the African continent in the past, as well as at present, is well shown on the maps on page 12 (rivers and lakes) and page 17 (the Sahara, Kalahari sands, and arid zones of the south-west and the horn of Africa). Distinction is made between old and new endemics, 'archeoendemics' tending not to have close relatives nearby, while 'neoendemics' may have related forms adjacent.

The main part of the work, Chapters 1-11, deals with the different sectors of African endemism, to some of which the author deliberately applies an archaic name-e.g. 'Incense coast' for the horn of Africa. He starts with the oceanic islands, as far west as Ascension and Tristan da Cunha and as far

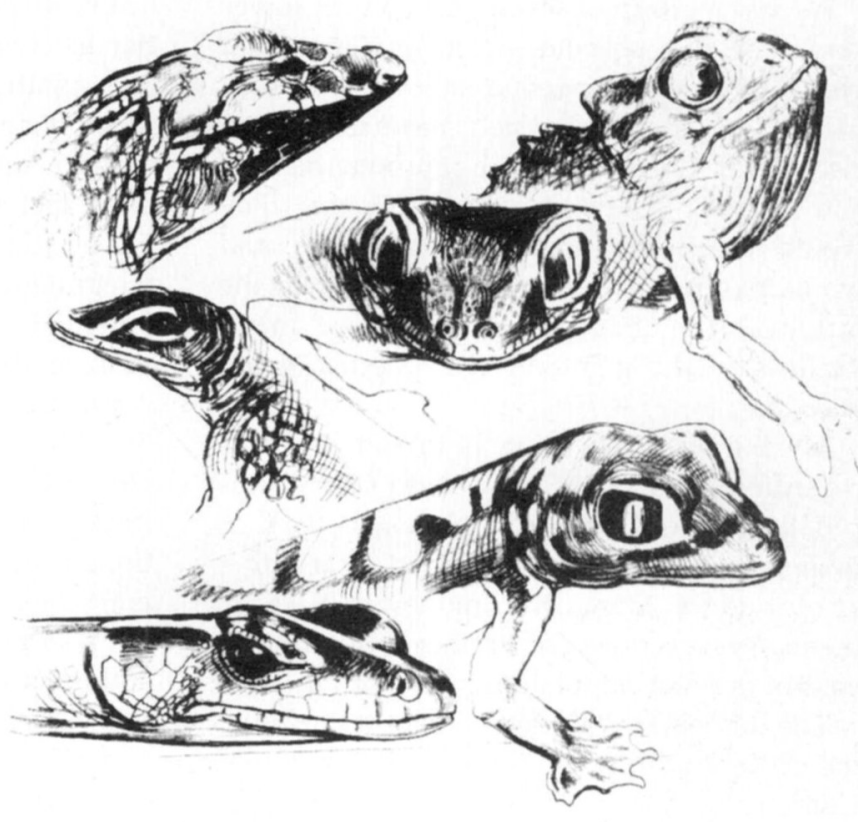

Namib reptiles, from Island Africa.

east as Rodrigues, as well as the shallow water islands closer to the African coast. Madagascar, although a major centre of endemism, is not part of the Afrotropical Region and is therefore omitted from detailed consideration, receiving only a few casual mentions. The author rightly draws attention to the vulnerability of ocean island endemics to subsequently introduced predators, usually cats, rats and mice, or introduced herbivores like goats. This does not apply, however, to the land-locked 'islands', which, despite their effect on the evolution and restricted distribution of endemics, have always been physically accessible to more widely and generally distributed terrestrial predators and herbivores.

Consequently, in the course of their evolution endemics of such enclaves had to retain the capacity to survive in the presence of predation (animals) or browsing and grazing (plants).
This must reduce their vulnerability to subsequent man-made introductions, which have been so disastrous on oceanic islands. The domestic cat for instance is not likely to pose much of an additional hazard to mainland endemic species already adapted to the presence of one or more wild felids.

The following nine chapters cover the mainland centres of endemism such as Ethiopia, the horn of Africa, the Zanj or 'Spice Coast' and others; while Chapter 11 deals with endemism in the aquatic systems associated mainly with the great lakes-Tanganyika, the oldest and deepest, the intermediate Malawi, and the largest, though youngest and shallowest, Victoria. This part is of course largely concerned with the numerous endemic fish, though it also touches on other species like the shoebill Balaeniceps rex and the Nile lechwe Kobus megaceros. Most of these accounts of particular 
centres of endemism conclude by drawing attention to present threats, and conservation measures needed to counteract them.

Chapter 12, 'Man-made islands-Reserves and National Parks', complements the main subject by drawing attention to the fragmentation of range of originally widespread species, which the author assesses as comprising about three-quarters of the total. The map on page 238 shows the national parks of sub-Saharan Africa, which represent what will be, and in many cases already are, the isolated refuges to which the more vulnerable species will be limited. They do of course include parts of the centres of endemism too. In theory these man-made islands could in time become centres of endemism acting on the isolated remaining populations of formerly widespread species. But many are unfortunately refuges only on paper with little or nothing being done on the ground, so the immediate concern must be to improve their status in the short- and medium-term future. The last chapter addresses some of the difficulties of conserving the centres of endemism, which in practice apply equally to the non-endemic conservation areas as well. There is today a heartening tendency, albeit belated by several decades, towards involving local communities in wildlife conservation and the author rightly stresses the importance of this.

Appendix I lists typical endemic species of the islands and enclaves, while Appendices II-V outline conservation needs in the countries in which centres of endemism lie, world heritage sites, biosphere reserves, national parks and reserves, and finally various conservation organizations with African interests both in and outside the continent.

Though it will be of considerable value to biologists and biogeographers, this is not a scientific treatise, but rather aimed at a broader readership, one of its declared objects being to advertise the existence of African centres of endemism and draw the attention of those interested outside Africa to their moral obligation to assist in conservation of these areas. It should do this and one hopes that it will. This book is good value at $£ 25$, being attractively produced, with a wealth of coloured and pencil illustrations in the author's characteristic and inimitable style. I recommend it to anyone interested in the wonderful fauna and flora it describes.

W. F. H. Ansell.

\section{The Natural History of Seals Nigel Bonner Christopher Helm, 1989, 196pp., HB £14.95}

This is an admirable summary of the natural history of seals, by a zoologist who is not only well qualified by his long service in the Antarctic but, unlike so many scientists, has a most pleasing writing style. It is not often that one can repeat oneself in reviewing successive books, but I am happy to be able to repeat the above sentence from my review of another book by the same author in the October 1989 Oryx, substituting only 'seals' for 'whales, porpoises and dolphins'. Marine mammal specialists usually cover both cetaceans and pinnipeds, but it is unusual to find one who couples thorough knowledge of both groups with such ability to convey scientific information in non-technical English.

To continue in the former vein, in only 196 well illustrated pages he has managed both to include much unusual information and to be right up to date on the true seals of the family Phocidae, the common, grey, harp and hooded seals and their relatives. The fur seals, sealions or walruses are not included.

While 'Save the Whale' has become the battle-cry of the activist section of the conservation movement, the activists have also chalked up the bans on harvesting and marketing the pelts of juvenile harp and hooded seals, especially from the Gulf of St Lawrence, as one of their major successes. Nigel Bonner deals percipiently with this vexed conflict between would-be but ham-handed sustainable harvesters and the outand-out 'no killing' animal welfare advocates. Seals have been a legitimate human prey since man began to occupy the northern part of the northern hemisphere, but when modern commercial pressures, including the media's taste for a good story with plenty of red blood on white fur, become dominant, the old relationship between hunter and hunted is gone forever. This was basically a political problem, appallingly badly handled by politicians, who were as reluctant as ever to be guided by impartial scientific advice and so became prisoners of the emotional crusade of the media and the activists.

Another aspect of man-seal relationships that Nigel Bonner deals with admirably is the age-old enmity between seals and fishermen, who want to kill seals primarily as competitors for fish, and only secondarily as a source of income. Fishermen are as reluctant as politicians (who are often guided by fishermen) to listen to scientists and their inconvenient facts, and believe the wildest 